\title{
Business Ethical Decisions In Kazakhstan
}

Carolyn Erdener, Kazakhstan Institute of Management, Economics and Strategic Research, Republic of Kazakhstan

\begin{abstract}
This paper is part of a larger study designed to explore the effects of ethnicity, nationality, and gender on responses to a variety of business ethical dilemmas in Central Asia. The data were collected in spring 2010 from MBA students at an American-style business school located in Kazakhstan. The findings are discussed in terms of their relevance to the conceptual categories of western philosophies of ethics (utilitarianism, deontology, individual rights, justice, etc.). Possible implications for managers of international and local firms operating in Central Asia are indicated. Suggestions for the next phase of this line of research are included. The study is ongoing and is presented as a work-in-progress, thus the findings are considered preliminary.
\end{abstract}

Keywords: Transitional Economy; Emerging Economy; Central Asia; Kazakhstan; Business Ethics

\section{INTRODUCTION}

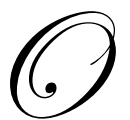

ne of the Newly Independent States (NIS) of the former Soviet Union (USSR), Kazakhstan is a very large country that is located practically equidistant from Europe, Russia, East Asia, Southeast Asia, India, West Asia, and the Middle East. Due to its vast natural resources in oil, gas, precious metals, uranium, rare earth, solar power, and agriculture, Kazakhstan is emerging as an international center for business and finance. It is also emerging as a powerhouse in the Central Asian region.

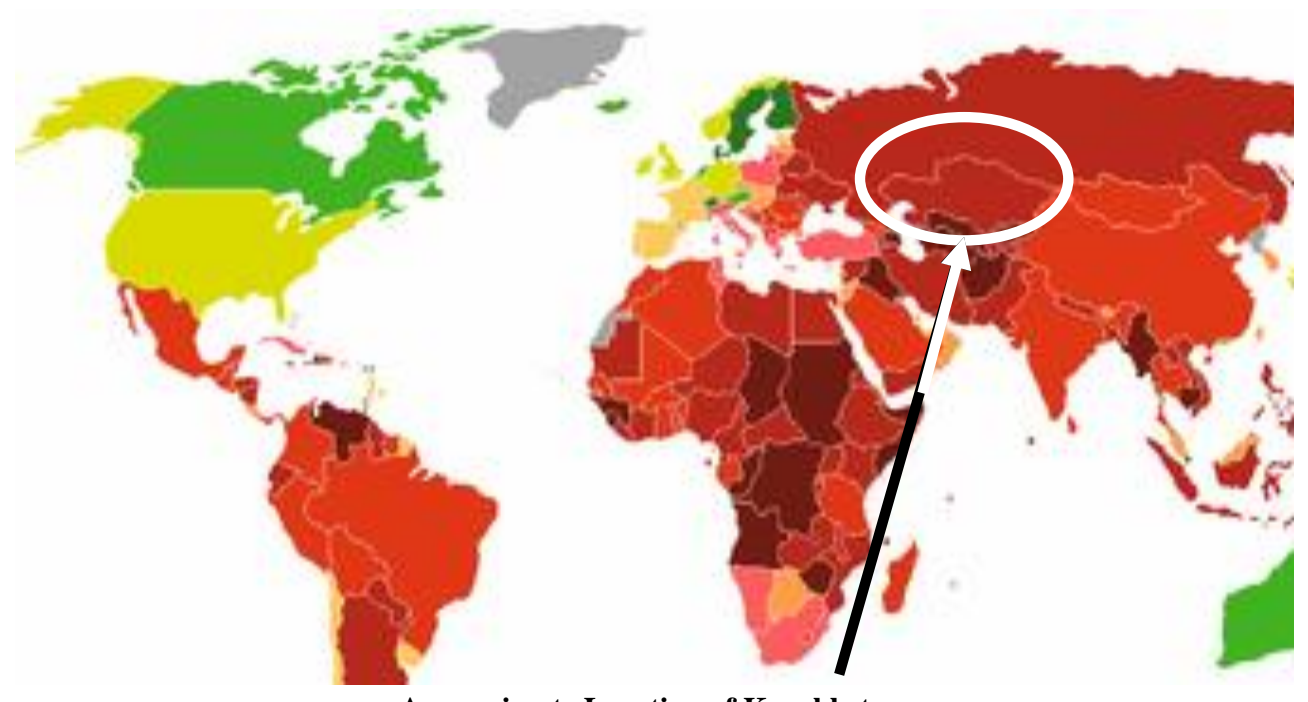

Approximate Location of Kazakhstan

\section{PURPOSE}

The purpose of this study is to lay the groundwork for gradually aligning managerial and organizational decision making in the region with global standards of ethical conduct of business. At the same time, it will facilitate greater understanding of local practices on the part of managers and organizations from outside the region. Both are necessary for successful integration of Kazakhstan into the global economy. 


\section{RESEARCH METHOD}

The subjects in this study were enrolled in an American-style MBA program at the Bang College of Business of the Kazakhstan Institute of Management, Economics and Strategic Research in Almaty, Kazakhstan. . It was administered in English in an English-speaking academic environment. Data were collected and analyzed in spring 2010.

The questionnaire used in this study is a modified version of a questionnaire that was originally developed by David Fritzsche and Helmut Becker (1984). It presents four out of five of the original short case scenarios and solicits responses from the subjects regarding what they would have done in each situation. All four scenarios involve an individual who is confronted with what may be considered an ethical dilemma. These scenarios have been used in a number of countries in Asia, Europe and Latin America, with interesting and meaningful results. (A copy of the questionnaire is in the Appendix.)

\section{STATISTICAL ANALYSIS}

Exploratory factor analysis was carried out separately on each of the four case scenarios used in this study. Interestingly, a different set of factors seems to emerge from the responses to each scenario. These are summarized below, with the factor loadings in parentheses following each associated questionnaire item.

Case 1: Rollfast bicycle. Three distinct factors are evident in the responses to the first case. The decision involves whether or not to pay a middleman $\$ 500,000$ for help in entering a lucrative new market. The first factor includes these items: "Would you pay the price?" (.932); "Why or why not - [is it] company policy?" (.925); and "[Why or why not - is it] bribery?" (.656). The second factor includes: "[Why or why not - does it cause] injury or harm?" (.842); and "[Why or why not - is it] local custom?" (.786). The third factor includes: "[Why or why not - is it] necessary for business?" (.602).

Case 1: Rollfast Bicycle

\begin{tabular}{|l|c|c|c|}
\hline \multirow{2}{*}{ Questionnaire Item } & \multicolumn{3}{c|}{ Component } \\
\cline { 2 - 4 } & $\mathbf{1}$ & $\mathbf{2}$ & $\mathbf{3}$ \\
\hline Would you pay the price? & $\mathbf{. 9 3 2}$ & -.140 & -.114 \\
\hline Why or why not - company policy? & $\mathbf{. 9 2 5}$ & .035 & .021 \\
\hline Legal issues? & .306 & .227 & .369 \\
\hline Bribery? & $\mathbf{. 6 5 6}$ & .350 & .478 \\
\hline Injury or harm? & .187 & $\mathbf{. 8 4 2}$ & -.401 \\
\hline Local custom? & .098 & $\mathbf{. 7 8 6}$ & -.453 \\
\hline Necessary for business? & -.241 & .561 &. $\mathbf{6 0 2}$ \\
\hline Other? & -.506 & .595 & .148 \\
\hline
\end{tabular}

Case 2: Master Millers. Another set of three distinct factors emerged in responses to the second case. The decision is whether or not to run a flour mill at night in order to hide the illegal amount of air pollution caused by old equipment. The first factor includes these items: "Would you approve the request?" (.859); "Why or why not[because of] legal issues?" (.817); and "[Why or why not - because of] environmental concerns?" (.857); "[Why or why not-because it's] not their fault?" (.839); and "[Why or why not - because of] possible injury or harm?" (.852). The second factor includes: "[Why or why not-because of] the risk of negative consequences? (.791); and "[Why or why not?]- other [reasons]? (.801) The third factor includes: "[Why or why not-because of] potential benefits?" (.804). 
Case 2: Master Millers

\begin{tabular}{|l|c|c|c|}
\hline \multirow{2}{*}{ Questionnaire Item } & \multicolumn{3}{c|}{ Component } \\
\cline { 2 - 4 } & $\mathbf{1}$ & $\mathbf{2}$ & $\mathbf{3}$ \\
\hline Would you approve the request? & $\mathbf{. 8 5 9}$ & .332 & -.335 \\
\hline Why or why not - Legal issues? & $\mathbf{. 8 1 7}$ & -.052 & .421 \\
\hline Environmental concerns? & $\mathbf{. 8 5 7}$ & .132 & .171 \\
\hline Risk of negative consequences? & -.262 & $\mathbf{. 7 9 1}$ & -.361 \\
\hline Not their fault? & $\mathbf{. 8 3 9}$ & .333 & .163 \\
\hline Possible injury or harm? & $\mathbf{- . 8 5 2}$ & .146 & .085 \\
\hline Potential benefits? & -.408 & .270 & $\mathbf{. 8 0 4}$ \\
\hline Other? & .242 & $\mathbf{. 8 0 1}$ & -.140 \\
\hline
\end{tabular}

Case 3: J \& P Publishing. Yet another set of three distinct factors appeared in responses to the third case. The managerial decision involves whether or not to publish a book that contains instructions for making a nuclear device (atom bomb). The first factor includes three items: "Would you publish the book?" (.957); "Why or why not world safety?" (.831); and "[Why or why not -] company image?" (.892). The second factor includes two items: [Why or why not - is the] information already available? (.795); and "[Why or why not?]- other [reasons]? (.805) The third factor consists of one item: "[Why or why not-because of] legal issues?" (.842).

Case 3: J \& P Publishing

\begin{tabular}{|l|l|l|l|}
\hline \multirow{2}{*}{ Questionnaire Item } & Component & 2 & 3 \\
\cline { 2 - 4 } & 1 & -.090 & .020 \\
\hline Would you do it? & $\mathbf{. 9 5 7}$ & -.089 & .459 \\
\hline Why or why not - World safety? & $\mathbf{. 8 3 1}$ & .026 & -.189 \\
\hline Company image? & $\mathbf{. 8 9 2}$ & -.417 & $\mathbf{. 8 4 2}$ \\
\hline Legal issues? & -.270 & $\mathbf{. 7 9 5}$ & .288 \\
\hline Information already available? & -.131 & $\mathbf{. 8 0 5}$ & .211 \\
\hline Other? & .160 & \\
\hline
\end{tabular}

Case 4: Auto Parts. Responses to the fourth case contained two clear factors. The decision problem is whether an employee at one of its supplier firms should notify an automobile manufacturer that the supplier is selling them defective parts which can cause life-threatening accidents. The first factor includes three items: "Why or why not [notify the auto manufacturer] - loyalty to the [supplier] company? (.608); "[Why or why not -] no injury or harm?;" and "Other [reasons]? (.670). The second factor includes: "Would you notify the auto manufacturer? (.891) and "[Why or why not?] - the firm's image? (-.826.

Case 4: Auto Parts

\begin{tabular}{|l|l|l|}
\hline \multirow{2}{*}{ Questionnaire Item } & Component & \multicolumn{2}{l|}{} \\
\cline { 2 - 3 } & 1 & 2 \\
\hline Would you notify the auto manufacturer? & -.207 & $\mathbf{. 8 9 1}$ \\
\hline Why or why not - loyalty to the company? & $\mathbf{. 6 0 8}$ & -.413 \\
\hline No injury or harm? & $\mathbf{. 8 7 7}$ & .366 \\
\hline Firm's responsibility to public? & .580 & .381 \\
\hline Firm's image? & .364 & $\mathbf{- . 8 2 6}$ \\
\hline Other? & $\mathbf{. 6 7 0}$ & .290 \\
\hline
\end{tabular}

\section{LIMITATIONS AND FUTURE EXTENSIONS}

One limitation of the approach developed by Fritzsche and Becker (1984) is that it doesn't differentiate between questionnaire items with positive versus negative effects on the various decisions. Yet the reasons why an individual would take a certain decision may be conceptually distinct from reasons why an individual would not take that decision. The structure of the questionnaire presumes that the same reasoning applies whether the effect is 
positive or negative, potentially confounding the results. In future research it would be worthwhile to clarify these effects. One way to do this would be to ask the subject to circle "would" or "wouldn't" in the phrase "why would you or wouldn't you..." etc. This would eliminate any possible ambiguity about what the respondent intends to communicate.

The original goal was to analyze gender effects on business ethical decision in a comparison of responses of males and females. This had to be temporarily set aside in the present stage of the research, however, due to an unanticipated imbalance in the number of males versus females in the final data set. The ratio of approximately $27 \%$ males to $73 \%$ females is atypical for the larger population.

The data were analyzed using exploratory factor analysis. Past experience has shown that this is necessary to shed light on cultural differences that may affect ethical reasoning in different contexts. For example, a situation that is seen in very practical, utilitarian terms in one culture may involve deontological moral principle in another culture. Since Kazakhstan has been at the crossroads of European, Middle Eastern and Asian cultures for many centuries, it is a synthesis of elements from all of them plus its own unique essence.

Comparing results of confirmatory factor analysis using the philosophical categories identified by Fritzsche and Becker (1984), with the results of exploratory factor analysis on data from Central Asia will be particularly informative for this reason.

It would be interesting to develop additional case scenarios to capture ethical dilemmas that are culturally appropriate in Central Asia and Kazakhstan. While the situations portrayed in the Fritzsche and Becker (1984) study have proven useful in identifying different response patterns across cultures, they cover a relatively small number of issues. Expanding this to include a much wider range of issues would provide additional value by shedding light on cultural patterns in the orientation of individual subjects to business ethics in practice.

\section{REFERENCES}

1. Etheredge, John \& Carolyn Erdener. 1999. "Ethical Decision Patterns in Four Countries: Contrasting Theoretical Perspectives," International Business Ethics: Challenges and Approaches, George Enderle, ed., University of Notre Dame Press, 51-66.

2. Fritzsche, D.J. \& Helmut Becker. 1984. "Linking Management Behavior to Ethical Philosophy--An Empirical Investigation." Academy of Management Journal, 27/1:166-175.

3. Fritzsche, D.J., Y.P. Huo, S. Sugai, S.D.H. Tsai, C.S. Kim \& H. Becker. 1995. "Exploring the Ethical Behavior of Managers: A Comparative Study of Four Countries." Asia Pacific Journal of Management, 12/2:37-61.

The following questionnaire was used in the study. It is a shortened version of the original Fritzsche and Becker instrument (Fritzsche and Becker, 1984). First, the scenarios have oeen simplified and shortened. Second, the range of responses to part (a) has been reduced in each case from the original ten to six. Third, likert-type scales have been added to facilitate statistical analysis. Respondents are asked to rate each of the suggested possible influences, rather than selecting a single item per case. 


\section{ROLLFAST BICYCLE}

I. Rollfast Bicycle Company has been kept out of the market in an Asian country by local bicycle manufacturers. Rollfast expects to earn 5 million dollars per year from sales if it can enter this market. Last week a businessman from the country contacted the management of Rollfast and said that he could smooth the way for the company to sell in his country for a price of $\$ 500,000$.

(a) If you were responsible, would you pay the price?

Circle one response:

$\begin{array}{llllllll}\begin{array}{l}\text { definitely } \\ \text { would } \frac{\text { not }}{0}\end{array} & 1 & 2 & 3 & 4 & 5 & \frac{\text { would }}{6}\end{array}$

(b) Why or Why not?

For each item, circle one number to show its influence on your decision.

1. COMPANY POLICY

Not Important

$\begin{array}{llllllll}0 & 1 & 2 & 3 & 4 & 5 & 6\end{array}$

2. LEGAL ISSUES

Not Important

$$
0
$$

1

2

34

5

Very Important

3. BRIBERY

Not Important

0

1

34

5

Very Important

4. INJURY OR HARM

Not Important

$0 \quad 1$

2

5. LOCAL CUSTOM

Not Important

$$
0
$$

1

2

6. NECESSARY FOR BUSINESS

Not Important

$\begin{array}{lll}0 & 1 & 2\end{array}$

7. OTHER (Please explain below.):

Not Important

$$
0
$$

$1 \quad 2 \quad 3$

34

$5 \quad \begin{array}{ll}\text { Very Important } \\ 5 & 6\end{array}$

Very Important

6

Very Important

6

6

Very Important

6 


\section{MASTER MILLERS}

II. Master Millers has developed a special process to make flour that provides a lighter, more even texture than common wheat flour. However, the process makes so much dust that the company cannot stay within the legal limit. Better equipment can reduce the dust, but will not be available for two years. If the company waits that long, it will lose the market for the new product. The general manager wants to use the new process late at night when the pollution will not be noticed in the dark, until the new equipment is available.

(a) If you were responsible, would you approve the general manager's request? Circle one response: definitely would not

$\begin{array}{llllll} & & & \begin{array}{l}\text { definitely } \\ \text { would }\end{array}\end{array}$

(b) Why or Why not? For each item, circle one number to indicate its influence on your decision.

1. LEGAL ISSUES

Not Important

$$
0
$$

1

2

\section{ENVIRONMENTAL CONCERNS}

Not Important

0

\section{RISK OF NEGATIVE CONSEQUENCES}

Not Important

$$
0
$$

1

2

34

4

5

Very Important

6

4. NOT THEIR FAULT

Not Important

0

1

2

5. POSSIBLE INJURY OR HARM

Not Important

$0 \quad 1 \quad 2$

6. POTENTIAL BENEFITS

Not Important

$0 \quad 1$

7. OTHER (Please explain below.)

Not Important

$$
0
$$

o 1

$\begin{array}{lll}0 & 1\end{array}$

below.)

2

3

4

5

Very Important

$$
6
$$

Very Important

6

Very Important

6

${ }_{6}^{\text {Very Important }}$

Very Important

6

Very Important

6 


\section{$\underline{\text { J \& P PUBLISHING }}$}

III. Tom Lee, senior editor of J\&P Publishing Company, has received a manuscript from one of his most successful authors, which provides a history of the development of the atomic bomb. The final chapter contains a detailed description of how the bomb is made, from other published sources. Jones has tried to convince the author to omit the last chapter, stating that such information should not be made readily available to the mass market in paperback form. The author believes the chapter is critical and will not agree to delete it.

(a) If you were Jones, would you publish the book? Circle one response:

$\begin{array}{llllllll}\begin{array}{l}\text { definitely } \\ \text { would } \frac{\text { not }}{0}\end{array} & 1 & 2 & 3 & 4 & 5 & \frac{\text { would }}{6}\end{array}$

(b) Why or Why not? For each item, circle one number to indicate its influence on your decision.

1. WORLD SAFETY

Not Important

$0 \quad 1$

2

34

5

Very Important

6

2. COMPANY IMAGE

Not Important

0

1

2

3. LEGAL ISSUES

Not Important

0

1

2

4. INFORMATION ALREADY AVAILABLE
Not Important

0

$\begin{array}{llllll}0 & 1 & 2 & 3 & 4 & 5\end{array}$

5. OTHER (Please explain below.):

Not Important

0

tant

1

3

4

$4 \quad 5$

Very Important

6

Very Important

6

Very Important

6

Very Important

Very
6 


\section{AUTO PARTS}

IV. Patrick Chan works in product development for an auto parts contractor. His company received a large contract to make parts for a major automobile manufacturer. This contract is very important to Patrick's firm, which almost had to lay off half of the firm's employees, including Patrick. In examining the test reports, Patrick discovered that they did not meet the manufacturers' requirements. Under certain conditions, these parts failed, which could result in serious injury or loss of life. He showed the test results to his supervisor and the company president, who said that they knew of the report and had decided to ignore it, because they would lose the contract if delivery of the parts were delayed. Jack must now decide whether to show the test results to the auto manufacturer.

(a) If you were Ward, would you notify the auto manufacturer? Circle one response: definitely

would $\frac{\text { not }}{0}$

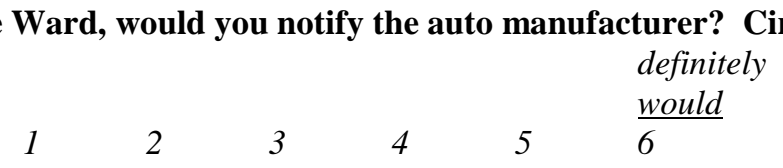

(b) Why or Why not? For each item, circle one number to indicate its influence on your decision.

\section{LOYALTY TO FIRM}

Not Important

0

1

(2)

\section{INJURY OR HARM}

Not Important

$0 \quad 1$

2

\section{FIRM'S RESPONSIBILITY TO PUBLIC}

Not Important

0

1

2

\section{4}

5

Very Important

4. FIRM'S IMAGE

Not Important

0

5. OTHER (Please explain below): Not Important

$$
0
$$

1

2

3

4

5

Very Important

6 